\title{
VARIAÇÕES DA TAXA DE AÇÚCAR NO LIQUIDO CEFALORRAQUEANO EM CASOS DE DERRAME DE SANGUE NO ESPAÇO SUB-ARACNÓIDE COM ESPECIAL REFERENCIA À HIPOGLICORRAQUIA
}

\author{
João Baptista dOS Reis Filho* \\ José Rodolfo Pasqualin ** \\ GiL José PACE ***
}

A diminuição da taxa de glicose no líquido céfalorraqueano (LCR) tem valor semiológico definido, podendo ocorrer em numerosas circunstâncias, quer devido a uma causa geral (hipoglicemia), quer devido a uma causa local. A segunda eventualidade - hipoglicorraquia originada por um mecanismo intrameningeo - tem grande importância no diagnóstico diferencial em Neurologia, ocorrendo em processos meningíticos sépticos bacterianos e por fungos, $\mathrm{cm}$ tumores malígnos do sistema nervoso central, na meningopatia leucêmica, em alguns casos de neurocisticercose e de paralisia geral progressiva e em casos de derrame de sangue no espaço sub-aracnóide.

De modo geral, em casos de hemorragia sub-aracnóide, a taxa de açúcar no LCR é normal ou aumentada, sendo raramente diminuída. A diminuição da taxa de glicose no LCR hemorrágico é assinalada nos manuais ${ }^{5,11,16} \mathrm{e}$ já fôra observado por Mestrezat em 1912 (cit. por Merritt e Fremont-Smith ${ }^{16}$ ). Merritt e Fremont-Smith verificaram em 21 pacientes com hemorragia subaracnóide sem causa aparente que, em 10, o LCR mostrava taxa de glicose inferior a $50 \mathrm{mg} / 100 \mathrm{ml}$, tendo sido um dos casos com $8 \mathrm{mg} / 100 \mathrm{ml}$. Estas taxas diminuidas, observaram êles, retornavam ao normal ràpidamente.

Madonick e col. ${ }^{15}$ fizeram revisão da literatura sôbre as variações da taxa de açúcar nos LCR de casos de hemorragia sub-aracnóide, assinalando que cinco autores observaram hipoglicorraquia inferior a $45 \mathrm{mg} / 100 \mathrm{ml} \mathrm{em}$ alguns de seus casos. Estes autores estudaram 59 pacientes com hemorragia sub-aracnóide não traumática e observaram glicorraquia inferior a $45 \mathrm{mg}$ / $100 \mathrm{ml}$ em 9 dêles, tendo sido $22 \mathrm{mg} / 100 \mathrm{ml}$ o menor valor. Eles estudaram também a relação entre a concentração da glicose no LCR e no sangue em 37 dêstes pacientes em jejum verificando que, em $1 / 3$ dêles, a relação estava nìtidamente diminuida. Êles não verificaram a existência de correlação entre

Trabalho do Departamento de Neurologia e Neurocirurgia da Escola Paulista de Medicina, apresentado ao IV Congresso da Academia Brasileira de Neurologia (Porto Alegre, julho de 1970): * Assistente voluntário; ** Médico estagiário; *** Professor Assistente do Departamento de Estatística da Faculdade de Ciências Econômicas e Administrativas da Universidade de São Paulo. 
as variações da taxa de glicose no LCR e o número de hemácias presentes, nem o intervalo de tempo que seguiu o início do processo hemorrágico.

Troost e col. ${ }^{20}$ constataram hipoglicorraquia em 5 de seus 21 casos de hemorragia sub-aracnóide, tendo sido $13 \mathrm{mg} / 100 \mathrm{ml}$ o menor valor encontrado. Eles verificaram que a hipoglicorraquia ocorria entre o sexto e oitavo dia depois do acidente inicial e sugeriram que êste achado seria mais freqüentemente observado se se fizessem exames seriados de LCR incluindo êste intervalo de tempo.

O propósito do presente trabalho foi o de estudar a variação cronológica da taxa de glicose no LCR em grande número de casos de derrame de sangue no espaço sub-aracnóide e, em particular, analisar os casos com hipoglicorraquia e verificar qual a prevalência de sua ocorrência durante o tempo de decurso da moléstia.

\section{MATERIAL E METODOS}

Foram selecionados 515 casos com diagnóstico de derrame de sangue no espaço sub-aracnóide nos quais a história permitia saber o dia do início da moléstia, bem como se a mesma era de causa traumática, ou não. Foram propositadamente excluídos os casos em que a hemorragia se associava a processo meningítico séptico ou ao diabete melito. Os 515 casos foram estudados em conjunto, bem como em dois lotes distintos, respeitando-se a etiologia do processo: traumatismo comprovado (156 casos) e outras etiologias (359 casos). Os pacientes foram submetidos a exame de LCR em datas diversas, do primeiro ao décimo dia de moléstia, em geral uma única vez cada doente. Para a finalidade dêste estudo as taxas de glicose foram agrupadas em funçāo do número de dias de evoluçāo da moléstia. As determinacoes da taxa de glicose foram efetuadas pelo método de Folin-Wu ${ }^{18}$, considerando-se como normais os valores compreendidos entre 50 e $80 \mathrm{mg} / \mathbf{1 0 0} \mathrm{ml}$. Foram feitos estudos estatísticos usando as médias ajustadas de cada dia, com a finalidade de verificar se, em determinado periodo de evoluçāo da moléstia, haveria hipoglicorraquia. $O$ estudo estatistico teve a finalidade de verificar se a hipoglicorraquia ocorreria em alguns periodo preferencial, tendo sido testada para tanto a hipótese de que as médias das taxas de glicose para cada periodo diário seria igual ou inferior a $50 \mathrm{mg} / 100 \mathrm{ml}$. Este estudo da distribuiçāo das taxas de glicose permitiu construir um diagrama de dispersão (valores observados), cuja função adequada é do tipo hiperbólico, ou seja:

$$
y=\frac{1}{A+B x}
$$

onde os parâmetros A e B foram calculados de acôrdo com o método dos Minimos Quadrados, através da equação:

$$
\hat{y}=\frac{1}{y}=A+B x(x-\bar{x})
$$

Os casos com hipoglicorraquia foram confrontados com dois outros grupos de mesmo número, e reunidos ao acaso, o primeiro com taxas de glicose normais e o segundo com taxas de glicose aumentadas. Estes casos foram analisados comparativamente em função da idade, da intensidade de xantocromia anotada em valores correspondentes ao indice ictérico ${ }^{3},{ }^{19}$, do número de hemácias por $\mathrm{mm}^{3}$, do número de células por $\mathrm{mm}^{3}$, da porcentagem de neutrófilos presentes e da taxa das proteinas totais. 


\section{R E S U L T A D O S}

Foi observado, no periodo compreendido entre o primeiro e o décimo dia de evoluçāo da moléstia, que as médias ajustadas da taxa da glicose correspondentes a cada dia tendiam de valores próximos ao limite superior de normalidade no primeiro dia, a valores em tôrno de $65 \mathrm{mg} / 100 \mathrm{ml}$ no décimo dia (Gráfico 1). Em nenhum dos periodos estudados a média ajustada ou real foi inferior a $50 \mathrm{mg} / 100 \mathrm{ml}$ e os testes estatísticos provaram, com uma confiança entre $95 \%$ e $99 \%$, que estas médias nāo podem ser consideradas inferiores a $50 \mathrm{mg} / 100 \mathrm{ml}$. Estes mesmos testes aplicados a cada grupo segundo as etiologias - traumática e não traumática mostraram o mesmo comportamento.

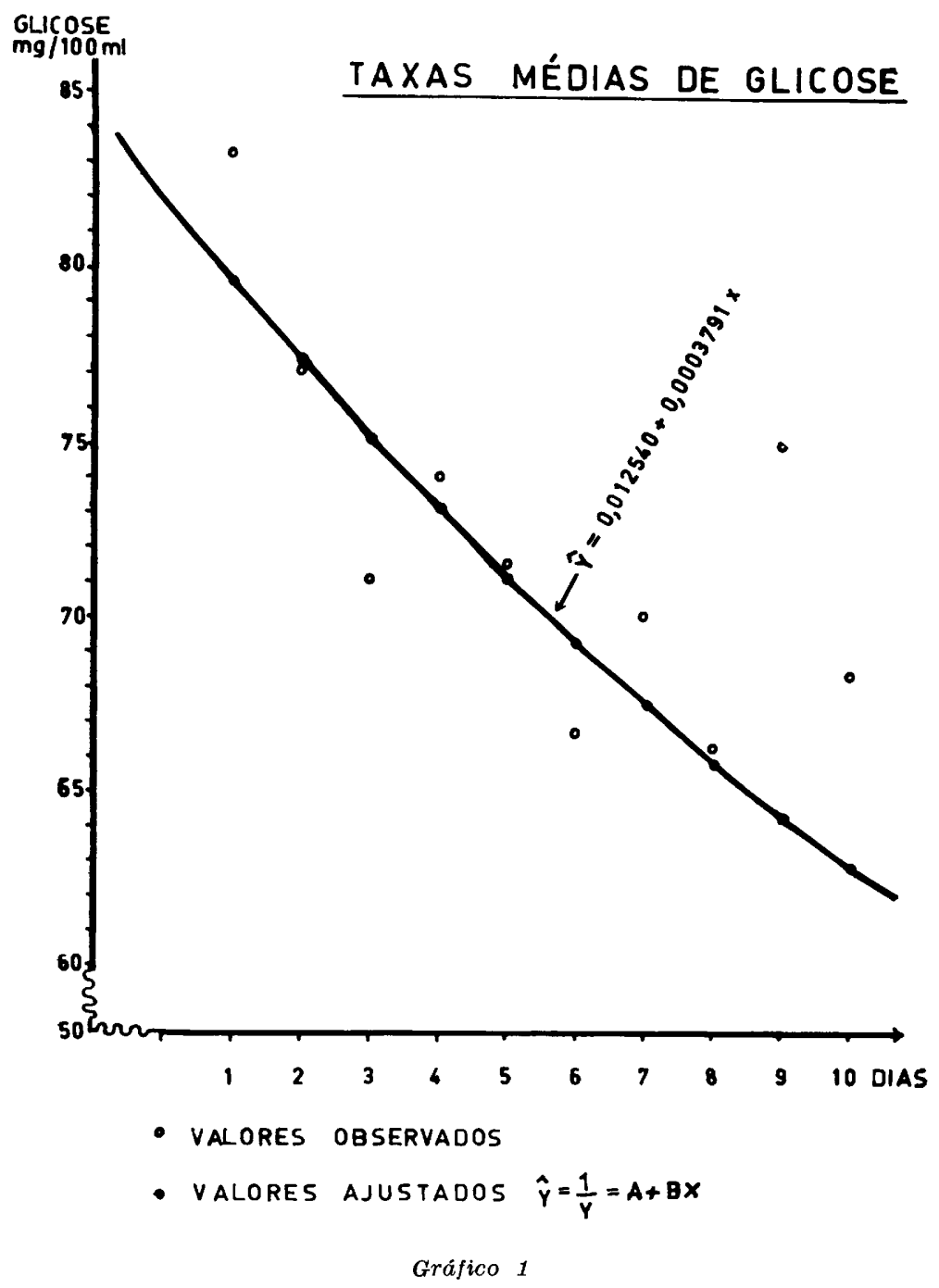


A maior taxa de glicose encontrada foi $245 \mathrm{mg} / 100 \mathrm{ml} \mathrm{e}$, e menor, de $12 \mathrm{mg} /$ $100 \mathrm{ml}$. A variação das taxas de glicose está resumida no quadro 1.

\begin{tabular}{cc}
\hline $\begin{array}{c}\text { Taxa de glicose } \\
\mathrm{mg} / 100 \mathrm{ml}\end{array}$ & Número de casos \\
\hline $12-40$ & 10 \\
$21-40$ & 10 \\
$41-49$ & 12 \\
$50-80$ & 304 \\
$81-245$ & 179 \\
\hline Quadro 1 - Distribuição dos casos de acôrdo com \\
as taxas de glicose no LCR.
\end{tabular}

Foram encontrados 32 casos com hipoglicorraquia, o que corresponde a $6,2 \%$ do total. Estes casos apresentaram distribuição uniforme dentro do periodo estudado, desde as primeiras 24 horas até o đécimo dia, não havendo prevalência para um determinado periodo de evolução da moléstia.

No confronto das variáveis do grupo de hipoglicorraquia com as mesmas variáveis dos outros dois grupos contrôle, foi assinalado um fato digno de nota: nos casos de hipoglicorraquia xantocromia era intensa, sempre acima do valor 1,0 da escala, enquanto que nos grupos com taxas de glicose normal ou aumentada a distribuição era uniforme, desde LCR incolores até fortemente xantocrômicos.

\section{O M E N TA R I O S}

De modo geral o mecanismo da glicólise no LCR não é bem compreendido 1, 10, 12, 23. Em relação ao mecanismo de origem da hipoglicorraquia nos LCR xantocrômicos obtidos em casos de hemorragia sub-aracnóide diversas teorias foram consideradas.

Numerosos estudos in vitro $2,6,10,17$ demonstraram que as hemácias e os leucócitos do sangue normal têm o poder de diminuir progressivamente a taxa de glicose. Guest e col. ${ }^{11}$ verificaram que o sangue normal consome $15 \mathrm{mg} \%$ de açúcar em uma hora. Blum, citado por Madonick e Savitzky ${ }^{15}$, e Merritt e Fremont-Smith ${ }^{16}$ sugeriram que a hipoglicorraquia observada nos casos de LCR hemorrágicos seria provàvelmente devida à presença de enzimas glicolíticas introduzidas no LCR juntamente com os glóbulos vermelhos do sangue. Madonick e Savitsky ${ }^{15}$ não conseguiram demonstrar a presença de enzimas glicolíticas nos LCR hemorrágicos nas suas experiências in vitro. Ao contrário, Froman e col. ${ }^{9}$ verificaram consumo da glicose em suas experiências com LCR artificial adicionado de grande quantidade de sangue.

Outra teoria lembrada para explicar a hipoglicorraquia é a perturbação da função da barreira hemato-encefálica 1, 5, 10, 12,13,15. Segundo esta 
hipótese haveria dificuldade para a passagem da glicose do sangue para o LCR em virtude da presença de elementos perturbadores dessa função. Esta teoria encontrou apôio nos trabalhos de Fishman ${ }^{7,8}$ que mostraram que a glicose se combina com um transportador movel de membrana sendo, então, transportada mais ràpidamente do que seria possivel por simples difusão. Fishman sugeriu que êste transportador movel de membrana poderia ser inibido competitivamente ou, mesmo, alterado por infiltrados celulares nas meninges, explicando-se, assim, o mecanismo patogenético da hipoglicorraquia associada a processos infecciosos ou neoplásicos das meninges. $\mathrm{Na}$ hemorragia sub-aracnóide poderia haver um mecanismo semelhante por interferência dos produtos de desintegração das hemácias ${ }^{20}$.

E muito provável que diversos mecanismos influam na origem da hipoglicorraquia.

O fato de havermos observado intensa xantocromia (acima do valor 1,0 da escala) em todos os casos de hipoglicorraquia, o que sugere a presença de grande quantidade de produtos de desintegração das hemácias, talvez possa estar de acôrdo com a teoria enzimática e a teoria do bloqueio da barreira hemato-encefálica.

Foi estudada a variação cronológica, do primeiro ao décimo dia, da taxa de glicose no LCR hemorrágico em 515 casos, sendo 156 conseqüente a traumatismos e 359 de outras etiologias. O objetivo principal do trabalho foi o de analisar, em particular, os casos de hipoglicorraquia e de verificar se esta ocorreria preferencialmente em determinado periodo de evolução do quadro hemorrágico. Os autores chegaram às seguinte conclusões: 1) houve tendência a valores elevados da glicorraquia nos primeiros dias do quadro hemorrágico e progressiva normalização nos dias subseqüentes; 2) a probabilidade da hipoglicorraquia ocorrer entre o $6 .^{\circ}$ e o $8 .^{\circ}$ dia do quadro hemorrágico não foi confirmada; 3) foi verificada a ocorrência de 32 casos de hipoglicorraquia, o que corresponde a $6,2 \%$ do total; 4) a xantocromia intensa verificada em todos os casos de hipoglicorraquia talvez deponha a favor da teoria enzimática e/ou da teoria do bloqueio da barreira hematoencefálica para a explicação do fato.

\section{S U M M A R Y}

Changes of sugar content in the cerebrospinal fluid of patients with subarachnoidal hemorrhage, with special reference to hypoglycorrhachia.

The chronologic changes of the glucose content in the hemorrahgic cerebrospinal fluid (CSF) in 515 cases have been studied, from the first to the tenth day. A traumatic origin was noticed in 156 cases and 359 were from miscellaneous origin. The diabetes mellitus and the meningitis cases were 
excluded from the study. The highest glucose content was $245 \mathrm{mg} / 100 \mathrm{ml}$ and the lowest one was $12 \mathrm{mg} / 100 \mathrm{ml}$.

The main purpose was to analyse the cases of low glucose levels in the CSF to find out if this would occur in a certain phase of the hemorrhagic event. The conclusions were the following: 1 . there was a tendency for high glucose levels in the first few days of the hemorrhagic episode and progressive normalization on the following days: 2 . the probability of occuring low glucose levels between the $6^{\text {th }}$ and $8^{\text {th }}$ day of the hemorrhagic event was not confirmed; 3 . there were 32 cases with hypoglycorrhachia $(6,2 \%$ of the total); 4. the intensive xanthochromia that was noticed in all cases with hypoglycorrhachia perhaps would be in behalf of the enzymatic theory and/or the theory of blood-brain barrier block in order to explain these findings.

\section{R E F E R E C I A S}

1. BALTCH, A. \& OSBORNE, W. - Inquiry into causes of lowered spinal fluid sugar content: in vivo and in vitro observations. J. Lab. \& Clin. Med. 49:882, 1957.

2. BARER, A. P. - Study of glycolysis. Arch. Int. Med. 10:507, 1931.

3. BERNHEIM, A. R. - The icterus index. J.A.M.A. 82:291, 1924.

4. CAStells, G. \& GHERARDI, J. - El Liquido Céfalo-raquídeo. Sind. Médico Uruguay, Montevideo, 1947.

5. DODGE, H. W.; SAYRE, G. P. \& SVIEN, H. J. - Sugar content of the cerebrospinal fluid in diffuse neoplastic involvemente of the meninges. Proc. Staff Meet. Mayo Clin. 27:259, 1952.

6. DOWDS, J. H. - A note on the distribuition of reducing sugar and the mode of glycolysis in human blood. Biochem. J. 20:1173, 1926.

7. FISHMAN, R. A. - Carrier transport and the concentration of glucose in cerebrospinal fluid in meningeal diseases. Ann. Int. Med. 63:153, 1965.

8. FISHMAN, R. A. - Carrier transport of glucose between blood and cerebrospinal fluid. Am. J. Physiol. 206:836, 1964.

9. FROMAN, C. \& SMITH, A. C. - Metabolic acidosis of the cerebrospinal fluid associated with subarachnoid hemorrhage. Lancet 1:965, 1967.

10. GOLDRING, S. \& HARFORD, C. G. - Effect of leucocytes and bacteria on glycose content of the cerebrospinal fluid in meningitis. Proc. Soc. Exp. Biol. \& Med., 75:669, 1950.

11. GUEST, G. M.; MACKLER, B.; GRAUBARTH, H. \& AMMENTORP, P. A. Rates of utilization of glucose in erythrocytes and leukocytes. Am. J. Physiol. 172:295, 1953.

12. HARFORD, C. G. - Comentários na discussão de caso anátomo-clínico. Am. J. Med. 20:275, 1956.

13. KIM, Y. S.; RESNICK, J. S. - Hypoglycorrhachia with meningeal carcinomatosis. Ann. Int. Med. 63:115, 1965.

14. LUPS, S. \& HAAN, A. M. F. H. - The Cerebrospinal Fluid. Elsevier, Asterdam. 1954.

15. MADONICK, M. J. \& SAVITSKY, N. - Spinal fluid sugar in subarachnoid hemorrhage. J. Nerv. Ment. Dis. 108:45, 1948.

16. MERRITT, H. H. \& FREMONT-SMITH, F. - The Cerebrospinal Fluid. W. B. Saunders, Philadelphia, 1938.

17. MORGUlis, S. \& BARKUS, O. - Studies on glycolysis in vitro. J. Biol. Chem. $65: 1,1925$.

18. REIS, J. B. \& SCHMIDT, H. - Técnica fotométrica para a dosagem das substâncias redutoras no líquído céfalorraqueano pelo método de Folin-Wu. Arq. Assist. Psicopatas de São Paulo 2:553, 1937. 
446 ARQ. NEURO-PSIQUIAT. (SÄO PAULO) VOL. 29, N.0 4, DEZEMBRO, 1971

19. SPURLING, R. G. \& MADDOCK, C. L. - The cerebrospinal fluid in tumor of the brain. Arch. Neurol. Psychiat. 14:54, 1925.

20. TROOST, B. T.; WALKER, J. E. \& SHERINGTON, M. - Hypoglycorrhachia associated will subarachnoid hemorrhage. Arch. Neurol. 19:438, 1968.

21. VARGA, F. \& KUN, C. - Contributory data concerning the decrease of sugar in the cerebrospinal fluid in meningitis. Res. in Am. J. Dis. Child. 83:556, 1952.

Departamento de Neurologia e Neurocirurgia - Escola Paulista de Medicina - Caixa Postal 5496 - São Paulo, SP - Brasil. 